\title{
A presença das artes em A Comédia Humana: do "pictural" ao künstlerroman
}

Milena Guerson, Programa de Pós-Graduação em Estudos Literários, Universidade Federal de Minas Gerais, Belo Horizonte, MG; $<$ milenaguerson@gmail.com>.1

\section{Resumo}

Referências à arte, em múltiplos aspectos e meios de expressão, constituem um fator recorrente nas narrativas de Balzac e, em geral, integram um procedimento de composição textual. Destacam-se duas possibilidades não excludentes entre si: a citação de nomes de artistas, obras e fatos que os circundam, conforme a realidade histórica; o uso de vocábulos artísticos, compondo metáforas e/ou trechos descritivos que incitam a criação de imagens mentais no leitor. As duas possibilidades auxiliam a situar os cenários e as situações das narrativas e, em muitos casos, conferem ao texto balzaquiano um caráter "pictural". Mas, embora as alusões à arte e aos artistas estejam presentes na diversidade de narrativas de $\boldsymbol{A}$ Comédia Humana, podemos elencar quatro textos em que a arte é especificamente tomada como eixo estruturador - apesar de diferentes gradações. Em "Sarrasine" (1830) há predomínio da escultura, enquanto "A obra-prima ignorada" (1831) focaliza a pintura. "Gambara" (1837) e "Massimila Doni" (1839) trazem uma abordagem sobre música. Em todos esses "romances de artista" vigoram reflexões ímpares sobre os trâmites da criação, destacando-se, apesar das respectivas ênfases dos enredos, alusões aos paralelos entre as artes, nos moldes da "tradição horaciana" - abordagem a partir da qual os atuais "estudos intersemióticos" têm origem.

Palavras-chave: ut pictura poesis, ekphrasis, descrição pictural, transposição de arte, romance de artista, Honoré de Balzac.

1 Este texto é resultado de um estudo mais amplo, referente à dissertação "Ressonâncias do ut pictura poesis em 'A obra-prima ignorada', de Honoré de Balzac", realizada no Mestrado em Estudos Literários, na UFMG, entre 2011 e 2013, com o apoio do CNPq. Atualmente, a autora é concluinte de um novo Mestrado, na área específica de Artes, na UFJF. 
Realizando uma estimativa inicial sobre a presença da arte e de artistas na obra balzaquiana, devemos considerar que $A$ Comédia Humana engloba 86 romances e novelas, segundo a avaliação de Paulo Rónai (1954: 9), e, quanto à presença específica da pintura neste conjunto, Nogacki (1999: 18) contabiliza setenta e três pintores citados "com maior ou menor freqüência", além de sete pintores fictícios de destaque. São, portanto, 80 pintores à disposição para 86 narrativas; e não estão incluídos aqui os demais artistas, como poetas, músicos, escultores, desenhistas, no que ainda maior se estima ser a importância da arte na obra balzaquiana. Robert Rey (1952: 177) destaca, entretanto, que dentre os dois mil personagens criados pelo escritor, os artistas plásticos (não só pintores) não chegam a totalizar vinte, o que nos leva a concluir que é mais fácil e prudente citar artistas do que fazê-los se tornar personagens fictícios.

Nogacki também busca mapear algumas prioridades de Balzac, quanto à citação de determinados pintores e estilos na totalidade da Comédia Humana, mas conclui que o escritor não possuía "um gosto claramente definido". Em vez de adotar um sistema estilístico, Balzac reúne os "que se encontram separados em função de opções estéticas" (1999: 26-27), priorizando a quantidade de menções aos nomes de pintores, em detrimento da observação das qualidades próprias a cada um deles. Por outro lado, Nogacki também pontua: "no que tange aos pintores de antes do Romantismo, a sensibilidade de Balzac é quase exclusivamente voltada para os caracteres humanos", ou seja, o "traço carregado de sentido" tem mais valor que o "efeito cromático de uma paisagem" (1999: 26).

Trata-se de uma informação relevante, pois agrega sentido à intercessão entre os aspectos psicológicos dos personagens e os traços mais "plásticos" ou físicos, que igualmente os caracterizam. Nogacki ressalta que os caracteres dos personagens balzaquianos estão fundamentados em asserções comparativas, constituídas pelo somatório do 
"elemento descritivo" com "uma primeira abordagem psicológica e moral do personagem" (1999: 20).

Michel Butor, no artigo Balzac e a realidade, comenta sobre o modo pelo qual Balzac compõe seus personagens. $O$ autor afirma que preponderam dois tipos em oposição: de um lado, as personagens históricas, que são "insubstituíveis" e possuem função de serem "reconhecidas", conforme dados verídicos, e por isso não permitem que o escritor divague muito sobre seus caracteres; de outro lado, as personagens "obscuras", próprias para serem "substituíveis", cujos nomes por vezes se escondem sob a função que exercem e sobre as quais muito se pode dizer, embora exijam a manutenção da verossimilhança. Entremeando estes pólos estão as personagens "célebres", cujos exemplos são os poetas ou os pintores e "cuja celebridade representará um papel na narrativa" (Butor, 1974: 93-94).

Butor especifica a configuração dos pintores e poetas fictícios como duplos de referentes reais. A menção a um poeta real é necessária para que o leitor reconheça o mundo literário contemporâneo ao autor, mas o poeta real deve ser apagado na moldagem do poeta fictício - um duplo não só verossimilhante, mas superior em celebridade; até porque os fictícios subsistirão, mesmo após o fim de seus modelos reais. Além desse fator, ante a necessária identificação entre indivíduo e grupo, um poeta célebre "suplanta toda uma categoria de poetas" e representa "uma quantidade de outros homens, dando-lhes de certa forma seu nome" (Butor, 1974: 94-97).

Desse modo, passando aos artistas com os quais Balzac se relaciona e que, então, constam ou influem em sua obra, podemos destacar: Decamps (1803-1860), Achille Devéria (1800-1857), Louis Boulenger (1806-1867) - (cf. Clouzot \& Valensi, 1926: 82) -, e, em especial, Delacroix (1798-1863), a quem o escritor dedica a narrativa "A menina dos olhos de 
ouro", e utiliza como modelo para a constituição do fictício Bridau (cf. Nogacki, 1999: 25).

Segundo François Fosca, é também Delacroix a fonte originária das ideias de mestre Frenhofer, personagem principal da narrativa "A obra-prima ignorada" (Rey, 1952: 189). Todavia, Teixeira Coelho destaca a discrepância entre as concepções do pintor romântico e os princípios que Frenhofer difunde; ele argumenta que a obra-prima que Frenhofer elabora melhor se aproxima da pintura de Willian Turner (1775-1850), chegando a indicar a possibilidade de que Balzac tenha visto obras de Turner em Paris ou em alguma viagem (Coelho, 2003: 82-85).

Outro nome de relevo é Girodet (1767-1824), pintor que, embora seja anterior à atuação de Balzac (Girodet morre em 1824, quando Balzac ainda não iniciara uma carreira autonoma como escritor), integra o grupo de artistas do primeiro império, citados como mestres e protetores dos fictícios Bridau ou Sommervieux - juntamente com Lemire, Gros, Gérard e Regnault - (cf. Clouzot \& Valensi, 1926: 84). Wettlaufer (2001: 2) aborda as conexões entre as obras de Girodet e Balzac, no sentido de, propiciamente, representarem as relações entre literatura e pintura, características do contexto da "França pósrevolucionária". Nogacki, por sua vez, retomando o prefácio de René Guise, para "A obra-prima ignorada", em edição da Pléiade Gallimard (cf. Nogacki: Balzac, CEuvres complètes, Pléiade Gallimard, t. X, p. 409 e seguintes), cita livros de História da Arte aos quais Balzac teve acesso:

La vie des peintres flamands, allemands et hollandais, de Jean Baptiste Descamps (Paris, 1753-1763), o Guide des amateurs de peinture, de Gault de Saint-Germain (Paris, 1817) e também, sem nenhuma dúvida, Les entretiens sur les vies et sur les ouvrages des plus excellents peintres anciens et modernes, de Félibien (Paris, 1666-1668). Colheram-se, assim, quase oitenta referências nesses livros enciclopédicos e biográficos, [...]. (Nogacki, 1999: 19).

Nogacki ainda afirma que estas referências serviram de base para estudos de Olivier Bonard, La Peinture dans la création balzacienne (1969), e de Pierre Laubriet, L'intelligence de l'art 
chez Balzac (1980), além de subsidiar artigos de críticos para as revistas Poétique e L'année balzacienne ${ }^{2}$. Em especial, quanto ao anuário, há numerosas publicações sobre a temática da arte em Balzac, em recortes diversos ${ }^{3}$. Outra fonte de relevo é o livro Balzac et la peinture, de 1999, que traz uma coletânea de artigos sobre o tema. Especificamente sobre pintura e poesia, além da obra de Wettlaufer, acima referida, podemos citar os seguintes artigos: Balzac, Frenhofer, Le Chef-d'œuvre inconnu: Ut Poesis Pictura (2000), de Kevin Bongiorni, e SelfPortraits of the Poet as a Painter, de Dominik Müller.

Em geral, os textos que tratam da presença ou das "influências" da pintura na obra de Balzac derivam e/ou ajudam a integrar um corpus de abordagens, próprias ao campo dos estudos intersemióticos, que trazem fundamentações sobre as qualidades da "pintura" aplicadas às diferentes modalidades textuais, desde os romances de ficção até a poesia. Dentre tais abordagens, destacam-se os estudos de Léo Hoek e Liliane Louvel, que apresentam propostas de classificação para diferentes "tipos" de interação entre literatura e pintura.

A partir de Hoek (2006: 168), podemos destacar o conceito de "transposição de arte", o qual, segundo o autor, é uma "moda século XIX", um "avatar moderno" da ekphrasis clássica, que consiste em "passar de um modo de expressão estética a outro (do pictural ao literário, ao musical, etc., ou inversamente)".

2 Dentre os artigos da revista Poétique, Nogacki destaca: Le tableau: description et peinture, de Bernard Vouilloux, e La toile déchirée, de Franc Schwerewegen (Nogacki, 1999: 19-20).

${ }^{3}$ Nogacki destaca o anuário número 59 , de 1986, que teve como tema "Être artiste". Também cabe destacar que os sumários dos exemplares dos anuários, dentre outras informações sobre vida e obra de Balzac (bibliografias, estudos, imagens), estão disponíveis para consulta no site: <http://www.balzac-etudes.parissorbonne.fr/balzac/index.html>. 
Retomando brevemente o conceito de ekphrasis, podemos defini-la como a "representação verbal" de uma "representação visual" e, sendo evidente a duplicidade do código, destacar que não se trata meramente de uma visualidade textual, mas de uma visualidade transposta em qualidades próprias às palavras (Clüver, 1997: 22).

Outro derivado da ekphrasis, desta vez na denominação de Louvel, é o conceito de "descrição pictural" (texto que evoca qualidades pictóricas, ou mesmo alude a um quadro específico) e que, segundo a autora, talvez seja o que "assegura a continuidade do ut pictura poesis" - no contexto dos "romances de artista" modernos, por exemplo. Conforme define Louvel, o "pictural" consiste na "aparição de uma referência às artes visuais em um texto literário, sob formas mais ou menos explícitas com um valor de citação, produzindo um efeito de metapicturalidade textual" (Louvel apud Arbex, 2006: 46). E o "pictural" também pode ser entendido no sentido "amplo e polissêmico" de "imagem" (Louvel, 2006: 192).

Sophie Bertho, em Asservir l'image, fonctions du tableau dans le récit, afirma que os aspectos picturais de um texto distribuem-se em quatro diferentes funções: a "função psicológica", na qual a referência pictural serve de reforço à voz narrativa ou caracteriza aspectos do ambiente e dos personagens; a "função estrutural", na qual a referência pictural sintetiza de modo emblemático certos aspectos da história, por vezes aspectos preditivos; a "função retórica", quando a referência pictural influi de modo persuasivo ou afetivo nas ideias de um personagem, ocasionando mudanças de concepções; por fim, a "função ontológica", quando a referência pictural atua de modo complexo, integrando as diferentes artes, pintura e literatura, em função da vida; relaciona-se com a capacidade da imagem em expressar o indizível, ou seja, uma presença pictural que expressa o que não se pode dizer por palavras (Bertho, 1990: 26-33). 
$\mathrm{Na}$ obra de Balzac podemos encontrar exemplos de uso dessas quatro funções, seja por alusões breves a artistas e obras reais ou pela própria ficcionalização destes artistas reais, pelo uso de transposições e/ou descrições picturais vinculadas a personagens e ambientes, ou mesmo quando a arte se torna tema ou designa elementos centrais do enredo. Neste último caso, adentramos o campo específico dos "romances de artista" (künstlerroman), um subgênero textual caracterizado pelo papel central que a arte, enquanto temática, assume na narrativa.

Em A Comédia Humana, há quatro textos em que a arte é especificamente tomada como eixo estruturador. Em "Sarrasine", de 1830, o foco é escultura, enquanto "A obraprima ignorada", de 1831, focaliza a pintura; estas duas narrativas se agrupam, pois tratam de artes que envolvem a visualidade (conforme o modelo do paragone ${ }^{4}$ ). "Gambara", de 1837, e "Massimila Doni", de 1839, trazem uma abordagem sobre música, e, assim, também se interligam em um subconjunto. Em todas as narrativas vigoram reflexões ímpares sobre os trâmites da criação, sendo possível localizar nos textos mais antigos parte da gênese dos conseguintes.

"Sarrasine", título que é também o nome do protagonista escultor, trata da paixão deste escultor pelo personagem Zambinella, sem considerar os costumes de representação de

${ }^{4}$ A partir do contexto renascentista, paralelamente ao ut pictura poesis (modelo de discussão que envolve a relação entre pintura e poesia), vigora um segundo tipo de comparação denominada paragone, que é própria às artes da visão (pintura e escultura) e que é primeiramente inserida "nos termos novos do humanismo" por Alberti. A tradição horaciana se liga ao paragone, "na medida em que a condição atribuída à pintura, em relação à poesia, determina a condição concedida à escultura em relação à pintura" (Lichtenstein, 2005: 9-10). 
papéis femininos por homens nos palcos romanos dos "estados Pontifícios". Idealizando uma beleza perfeita de mulher, dá corpo a uma estátua da amada, mas quando descobre que Zambinella é um homem, tem seu ideal de perfeição desmoronado - o amor e a arte são ilusões. Sarrasine morre assassinado, a mando do protetor de Zambinella; a família deste, os "de Lanty", acaba enriquecendo à custa do ocorrido, devido a uma trama que se desdobra a partir da estátua que o escultor deixara em vias de acabamento (Balzac, 1954: 553587).

Em "A obra-prima ignorada", Frenhofer, o protagonista pintor, acredita ser capaz de compor uma pintura perfeita. Como mestre, se dedica a explanar sobre pintura para dois outros "discípulos", revelando segredos de composição e exaltando como emprega esses segredos em sua tela laboriosa, em relação à qual possui um vínculo de amor. Por fim, a obra perfeita do mestre se revela incompreensível para os discípulos. Frenhofer morre após, supostamente, atear fogo em suas obras; os fatos finais repercutem abruptamente na vida dos outros dois pintores (Balzac, 1954: 385-412).

Em "Gambara", o músico protagonista acredita ser o renovador incompreendido da arte musical de seu tempo, elabora composições e instrumentos novos, os quais somente consegue fazer valer em estado de embriaguez. Quando está sóbrio, seus trabalhos se revelam como fragmentos desconfigurados - segundo os ouvintes, sons desconexos ao acaso, ruídos importunos. O músico insiste na sobriedade de sua concepção artística e, defendendo a lucidez que, aos olhos dos outros, é incompreensível, acaba na miséria. Perde sua esposa, suas composições e os instrumentos diferenciados que fabricou, embora recupere ligeira parte dessas benesses no final do enredo. Acaba como músico de rua, apresentando, junto à esposa e sob o efeito de álcool, os trechos que recorda das composições que perdeu (Balzac, 1954: 413-469). O fator por excelência a ser destacado no universo de criação do 
músico Gambara, irmão gêmeo grotesco de Frenhofer, segundo Rónai (1954: 416), é "o caráter irreal dessa obra de arte total, que seu autor traz em si sem nunca poder dar senão percepções incompletas ou fragmentos truncados".

Em "Massimila Doni”, um jogo amoroso se constrói no contexto da ópera em Veneza. Emílio Memmi ama Massimila, esposa do duque Cataneo, o qual é mantenedor de Clarina Tinti, cantora de ópera, pela qual Genovese - tenor que a acompanha - se apaixona. Nessa atmosfera de relações são discutidos conceitos sobre música, a qual, em muitos casos, é comparada às outras formas de arte. Massimila Doni (Duquesa Cataneo), que aparece em uma simples menção no final da narrativa "Gambara", torna-se protagonista na narrativa que recebe seu nome e na qual são retomados e aprofundados preceitos difundidos por Gambara; estes fatos acentuam o grau de interligação entre os textos. (Balzac, 1954: 307-384). Adjetivando "Massimila Doni" como uma narrativa "recalcitrante", Rónai (1954: 309) afirma que Balzac protela a finalização da trama por algumas vezes - ao que podemos acrescentar -, semelhante à maneira pela qual seus personagens artistas protelam a busca pelo sentido da criação.

O que caracteriza a similaridade presente nos "romances de artista" balzaquianos são, em grande medida, as vigentes ideias sobre o paralelo das artes, e, mais especificamente, sobre o vínculo entre pintura e poesia. O escritor costuma utilizar fartas metáforas, indicando que há poesia em tudo - no mundo, nas coisas -, e se a pintura representa as coisas e o mundo, há frequentemente poesia na pintura. Neste ponto, deve-se distinguir que não apenas nos "romances de artista", mas, sim, em qualquer romance, pode haver aspectos "picturais" - geralmente localizados em passagens de cunho descritivo -, embora tais aspectos transpareçam sobremaneira nas narrativas que tomam a arte como tema; onde, além da "metapicturalidade", que se coloca no nível da linguagem, 
desdobram-se reflexões teóricas e/ou filosóficas sobre os sentidos da criação.

Especificando temáticas próprias à discussão do ut pictura poesis ${ }^{5}$ presentes nestes romances, podemos mencionar: a impossibilidade da perfeição, do alcance do belo em arte, vinculada à impossibilidade da representação plena da vida, do real; a discussão sobre a relação entre ciência e inspiração; a relação entre a arte e o amor - desejo e paixão pela criação, em contraponto à razão; a oposição entre as faces material e espiritual da arte; a existência de um elo comum entre as artes; a necessidade de uma expressão poética como inspiração para os demais meios artísticos.

É perene a busca por algo diferenciado na arte que se visa a empreender e sempre há um quesito poético que sustenha, sob os sopros das musas ou de claridades celestes, uma criação divina e, uma vez estando fora da esfera do "humano", uma criação algo sobrenatural ou mesmo demoníaca. Balzac exprime o que é indefinível para o "humano" diante da criação e, por isso, envolve os liames da lucidez e da loucura; mazelas de artistas "divinizados" ou visionários, em um mundo material pleno de paixões. Neste ensejo, vale ressaltar o paralelo que Balzac elabora quando procura demonstrar os vieses da "virtude" em sua obra, respondendo aos que o acusavam de imoralidade: "Para criar muitas Virgens é preciso ser Rafael. A literatura, sob esse ponto de vista, está, talvez, abaixo da pintura". (Balzac, 1954: 19).

${ }^{5}$ A máxima ut pictura poesis é proveniente do pensamento de Horácio (século I a.C.), no texto intitulado Epístola aos Pisões ou, conforme denomina Quintiliano, Ars Poetica, mas Solange Oliveira (1993) aponta que, ultrapassando a acepção deste contexto originário, a máxima irá, através de processo gradual, configurar uma "abordagem crítica", que discute as relações entre pintura e poesia (Oliveira, 1993: 13). 
No estudo introdutório que realiza para "Gambara", Rónai (1954: 415) afirma que Balzac insiste "sobre a unidade e a inseparabilidade das artes". O autor expõe que na carta ao editor da revista, na qual a narrativa seria publicada pela primeira vez, Balzac "convida o destinatário a ler as páginas de E.T.A. Hoffmanm sobre Gluck, Mozart, Haydn e Beethoven, para compreender "por que leis secretas a literatura, a música e a pintura estão ligadas entre si”. Já no estudo introdutório sobre "Massimila Doni", Rónai (1954: 310-311) destaca a divergência do julgamento da crítica, apontando que para Camille Bellaigue, Balzac discorre sobre a "essência da música", defendendo "sua superioridade sobre a literatura e as demais artes"; enquanto para L. Maurice-Amour, Balzac realiza qualquer outra coisa, menos abordar plenamente a música: "sonha sobre a música [...], empresta-Ihe suas ficções, colore-a de sua pintura, veste-a de literatura, dá-lhe de vez em quando um vago alcance filosófico". De fato, o escritor não deixa de exaltar a música, nem de abranger "regiões extramusicais", pois aborda os antagonismos e as permeações interartes.

Ao elaborar "A obra-prima ignorada", Balzac transpõe para uma novela sobre pintura o enredo de um conto fantástico sobre música, "A aula de violino", de E.T.A. Hoffman. A narrativa de Balzac é composta a partir de uma encomenda da revista L'Artiste, que apresenta a Balzac, como modelo, a linha de escrita do autor alemão. Ideias centrais da trama de músicos serão mantidas na trama de pintores - inclusive a nomenclatura "conto filosófico", que acompanha o título do texto de Balzac na primeira publicação, de 1831. Teixeira Coelho (2003: 110-111) aponta como diferença básica entre as narrativas o fato de que Balzac deixa margem para que encontremos em Frenhofer um "discurso renovador", enquanto o velho músico, no enredo de Hoffman, age como um gênio, mas não entende de música verdadeiramente, não sabe manejar um instrumento, gerando sons desconcertantes, assim como acontece com Gambara. 
$\mathrm{Na}$ opinião de Michel Butor, Frenhofer e Gambara, "pintor e músico inverossímeis", inclusive por estarem situados na parte de Estudos Filosóficos, "resumem, esclarecem e levam até certo limite os pintores ou os músicos que aparecem" nas demais seções de A Comédia Humana. Butor argumenta que os Estudos Filosóficos demarcam as narrativas balzaquianas nas quais há "maior deslocamento com relação ao cotidiano", possuindo função de esclarecimento e contradição em relação aos precedentes "estudos sociais", mais afeitos ao real (Butor, 1974: 98-99). Este fato chama a atenção para a tônica do "questionamento filosófico" presente nas narrativas sobre arte de que tratamos. Taine evidencia 0 aspecto reflexivo de Balzac, quando "o filósofo se casa ao observador. Vê, em seus detalhes, as leis que os encadeiam" (Curtius, 1954: 22).

Segundo Rónai (1954: 309), o central problema artísticofilosófico das narrativas balzaquianas engloba "a desordem que o pensamento chegado a seu completo desenvolvimento produz na alma do artista, explicando por que leis se chega ao suicídio da arte". O sentido da criação artística é visto como uma incógnita perene... $\mathrm{Na}$ tentativa de solução desta incógnita, as artes serão "comparadas" entre si, mas todos os meios, sem distinção, retornam ao "ponto cego" da criação. Assim, o sentido das "artes" passa a residir, sempre, na continuidade do próprio "fazer" artístico e dos diálogos entre elas. Na esteira desses diálogos, podemos acrescentar, a título de finalização do presente texto, o jogo inverso da relação texto-imagem, quando outros artistas virão a ilustrar ou promover peças teatrais e filmes baseados nos textos de Balzac.

\section{Referências}

Arbex, M. (2006). Poéticas do visível: uma breve introdução. In . (Org.). Poéticas do visível: ensaios sobre a escrita e a imagem. Belo Horizonte: FALE UFMG.

Balzac, Honoré de. (1954). A comédia humana. (15 volumes). Introduções, notas e orientação: Paulo Rónai. Porto Alegre: Globo. 
(1954). A obra-prima ignorada. In

A comédia

humana: estudos filosóficos. (Vol. 15). Porto Alegre: Globo.

(1954). Gambara. In A comédia humana: estudos

filosóficos. (Vol. 15). Porto Alegre: Globo.

Massimila Doni. (1954). In A comédia humana:

estudos filosóficos. (Vol. 15). Porto Alegre: Globo.

Sarrasine. (1954). In A comédia humana: estudos de costumes: cenas da vida parisiense. (Vol. 9). Porto Alegre: Globo.

Prefácio à comédia humana. (1954). In A comédia

humana: estudos de costumes: cenas da vida privada. (Vol. 1). Porto Alegre: Globo.

Bertho, S. (1990). Asservir l'image: fonctions du tableau dans le récit. In Hoek, L. H. (Org.). L'Interprétation détournée. Amsterdam: Rodopi.

Bongiorni, K. P. (2000). Balzac, Frenhofer, Le chef-d'œuvre inconnu: ut poesis pictura. In: MOSAIC, 2 (33), 87-99.

Boyer, J. P., \& Boyer, E. (1999). Balzac et la peinture. Musée des Beaux-Arts de Tours: Farrago.

Butor, M. (1974). Balzac e a realidade. In Michel Butor: repertório. São Paulo: Perspectiva.

Clouzot, H., \& Valensi, R.-H. ( 1926). Peinture et sculpture. In Le paris de la comédie humaine: Balzac et ses fournisseurs. Paris: Le Goupy Editeur.

Clüver, C. (1997). Ekphrasis reconsidered: on verbal representations of non-verbal texts. In Lagerroth, U., Lund, H., \& Hedling, E. (Eds.). Interart poetics: essays on the interrelations of the arts and media. Amsterdam: Rodopi.

Coelho, T. (2003). Entre a vida e a arte. In . (Ed.). A obraprima ignorada. São Paulo: Comunique.

Curtius, E. R. (1954). A influência de Balzac. In Balzac, Honoré de. A comédia humana: estudos filosóficos. (Vol. 15). Porto Alegre: Globo.

Hoek, L. (2006). A transposição intersemiótica: por uma classificação pragmática. In Arbex, M. (Org.). Poéticas do Visível: ensaios sobre a escrita e a imagem. Belo Horizonte: FALE UFMG.

Lichtenstein, J. (2005). O paralelo das artes. In: (Org.). $A$ Pintura: textos essenciais. (Vol. 7). São Paulo: Ed 34, 2005. 
Louvel, L. (2006). A descrição "pictural": por uma poética do iconotexto. In Arbex, M. (Org.). Poéticas do Visível: ensaios sobre a escrita e a imagem. Belo Horizonte: FALE UFMG.

Müller, D. (1997). Self-Portraits of the Poet as a Painter: Narratives on Artists and the Bounds between the Arts (Hoffmann - Balzac - Stifter). In Morrison, J. \& Krobb, F. (Eds.). Text into Image Image into Text. Amsterdam: Rodopi.

Nogacki, E. (1999). Honoré de Balzac : Do pintor real à personagem romanesca. In Costa, H. B. A. et al. Balzac: a obra-mundo: o colóquio de São Paulo. São Paulo: Estação Liberdade.

Oliveira, S. R. (1993). Literatura \& Artes Plásticas: o künstlerroman na ficção contemporânea. Ouro Preto: Editora UFOP.

Rey, R. (1952). Les Artistes. In DURON, Jacques-Robert et al. Balzac: le livre du centenaire. Paris: Flammarion.

Rónai, P. (1954). Massimila Doni: Introdução. In Balzac, Honoré de. A comédia humana: estudos filosóficos. (Vol. 15). Porto Alegre: Globo. (1954). Gambara: Introdução. In Balzac, Honoré de. A comédia humana: estudos filosóficos. (Vol. 15). Porto Alegre: Globo. Wettlaufer, A. K. (2001). Pen vs. Paintbrush: Girodet, Balzac and the Myth of Pygmalion in Postrevolutionary France. New York: Palgrave. 